\title{
The effects of vitamin $D, K$ and calcium co-supplementation on carotid intima-media thickness and metabolic status in overweight type 2 diabetic patients with CHD
}

\author{
Zatollah Asemi ${ }^{1}$, Fariba Raygan ${ }^{2}$, Fereshteh Bahmani ${ }^{1}$, Zohreh Rezavandi ${ }^{2}$, Hamid Reza Talari ${ }^{3}$, \\ Motahereh Rafiee ${ }^{3}$, Somayyeh Poladchang ${ }^{3}$, Manijeh Darooghegi Mofrad ${ }^{1}$, Sara Taheri ${ }^{1}$, \\ Ali Akbar Mohammadi ${ }^{1}$ and Ahmad Esmaillzadeh ${ }^{4,5,6 *}$ \\ ${ }^{1}$ Research Center for Biochemistry and Nutrition in Metabolic Diseases, Kashan University of Medical Sciences, Kashan, \\ Islamic Republic of Iran \\ ${ }^{2}$ Department of Cardiology, School of Medicine, Kashan University of Medical Sciences, Kashan, Islamic Republic of Iran \\ ${ }^{3}$ Department of Radiology, Kashan University of Medical Sciences, Kashan, Islamic Republic of Iran \\ ${ }^{4}$ Food Security Research Center, Isfahan University of Medical Sciences, Isfahan, Islamic Republic of Iran \\ ${ }^{5}$ Department of Community Nutrition, School of Nutrition and Food Science, Isfahan University of Medical Sciences, Isfahan, \\ Islamic Republic of Iran \\ ${ }^{6}$ Department of Community Nutrition, School of Nutritional Sciences and Dietetics, Tehran University of Medical Sciences, \\ Tehran, Islamic Republic of Iran
}

(Submitted 18 December 2015 - Final revision received 30 March 2016 - Accepted 8 April 2016)

\section{Abstract}

This study was conducted to examine the effects of vitamin D, K and Ca co-supplementation on carotid intima-media thickness (CIMT) and metabolic status in overweight diabetic patients with CHD. This randomised, double-blind, placebo-controlled trial was conducted among sixty-six diabetic patients with CHD. Participants were randomly allocated into two groups to take either $5 \mu \mathrm{g}$ vitamin D, $90 \mu \mathrm{g}$ vitamin K plus $500 \mathrm{mg}$ Ca supplements ( $n$ 33) or placebo ( $n$ 33) twice a day for 12 weeks. Fasting blood samples were obtained at the beginning of the study and after the 12 -week intervention period to determine related markers. Vitamin D, K and Ca co-supplementation resulted in a significant reduction in maximum levels of left CIMT ( $-0.04(\mathrm{sD} 0 \cdot 22) v .+0.04(\mathrm{sD} 0.09) \mathrm{mm}, P=0.02)$. Changes in serum vitamin $\mathrm{D}(+6 \cdot 5$ (sD $7 \cdot 8) v .+0 \cdot 4(\mathrm{sD} 2 \cdot 2) \mathrm{ng} / \mathrm{ml}$, $P<0.001)$, Ca $(+0.6(\mathrm{sD} 0.3) v \cdot+0 \cdot 1(\mathrm{sD} 0 \cdot 1) \mathrm{mg} / \mathrm{dl}, P<0.001)$ and insulin concentrations $(-0.9$ (sD $3 \cdot 1) v .+2 \cdot 6$ (sD $7 \cdot 2) \mu \mathrm{IU} / \mathrm{ml}, P=0 \cdot 01)$, homoeostasis model for assessment of estimated insulin resistance ( -0.4 (SD 1.2) $v$. +0.7 (sD 2.3), $P=0.01$ ), $\beta$-cell function $(-2 \cdot 1$ (sD 9.0) $v$. +8.9 (sD 23.7), $P=0.01$ ) and quantitative insulin sensitivity check index ( +0.007 (sD 0.01) $v .-0.006$ (sD 0.02), $P=0.01$ ) in supplemented patients were significantly different from those in patients in the placebo group. Supplementation resulted in significant changes in HDL-cholesterol (+2.7 (sD 7.0) $v$. -2.5 (sD 5.7) $\mathrm{mg} / \mathrm{dl}, P=0.002$ ), high-sensitivity C-reactive protein $(-1320.1$ (sD 3758.3) $v .+464.0$ (sD 3053.3 ) ng/ml, $P=0.03$ ) and plasma malondialdehyde concentrations $(-0.4$ (sD 0.5$) v .-1.0$ (sD 1.1) $\mu \mathrm{mol} / \mathrm{l}, P=0.007$ ) compared with placebo. Overall, vitamin $\mathrm{D}, \mathrm{K}$ and $\mathrm{Ca}$ co-supplementation for 12 weeks among diabetic patients with CHD had beneficial effects on maximum levels of left CIMT and metabolic status. The effect of vitamin D, K and Ca co-supplementation on maximum levels of left CIMT could be a chance finding.

Key words: Vitamin D, K and calcium co-supplementation: Carotid intima-media thickness: Metabolic status: Type 2 diabetes mellitus: CHD: Obesity

Type 2 diabetes mellitus (T2DM) and visceral obesity are closely associated with some long-term consequences such as dyslipidaemia, retinopathy, chronic renal disease and $\mathrm{CHD}^{(1)}$. Hyperglycaemia, insulin resistance and intra-parietal accumulation of advanced glycation end products in patients with T2DM would result in macrovascular alterations through the activation of different pathways, particularly NF- $\kappa$ B and mitogen- activated protein kinase ${ }^{(2)}$. Recently, a few studies have evaluated the relationship between carotid intima-media thickness (CIMT) and the metabolic syndrome (MetS). Several studies have reported a significant positive association between CIMT and diabetes, blood pressures, lipid profiles and inflammatory cytokines ${ }^{(3,4)}$, whereas other studies have not reported any significant association between the MetS and CIMT ${ }^{(5)}$.

Abbreviations: CIMT, carotid intima-media thickness; FPG, fasting plasma glucose; HOMA-IR, homoeostasis model for assessment of insulin resistance; hs-CRP, high-sensitivity C-reactive protein; MDA, malondialdehyde; MGP, matrix Gla-protein; NO, nitric oxide. 
Decreased vitamin D levels were associated with increased $\mathrm{CIMT}^{(6)}$, insulin resistance and inflammation ${ }^{(7)}$. Furthermore, Braam et $a l^{(8)}$ found that long-term supplementation with vitamins $\mathrm{K}_{1}(1 \mathrm{mg})$ and $\mathrm{D}(8 \mu \mathrm{g})$ had beneficial effects on elastic properties of the carotid artery in postmenopausal women, but it did not influence CIMT. A 270-d course of vitamin $\mathrm{K}_{2}$ supplementation at a dose of $90 \mu \mathrm{g}$ (menaquinone (MK)-7) in patients with coronary vascular disease reduced the progression of atherosclerosis and $\mathrm{CIMT}^{(9)}$. Moreover, two recent studies have shown that $\mathrm{Ca}$ and vitamin $\mathrm{D}$ co-supplementation had beneficial effects on metabolic profiles ${ }^{(10,11)}$. Vitamin $\mathrm{K}$ supplementation for 36 months at a dose of $500 \mu \mathrm{g} / \mathrm{d}$ also decreased progression of insulin resistance in older men ${ }^{(12)}$.

We assume that vitamin D, K and Ca co-supplementation might influence CIMT by improving insulin function as well as biomarkers of inflammation and oxidative stress. Such beneficial effects might be mediated through the beneficial effect on the elastic properties of the arterial vessel wall ${ }^{(8)}$, the regulation of cell cycle $^{(13)}$ and suppression of parathyroid hormone $(\mathrm{PTH})^{(14)}$. We are aware of no study that assessed vitamin $\mathrm{D}, \mathrm{K}$ and $\mathrm{Ca} \mathrm{CO}^{-}$ administration on CIMT and metabolic status in overweight T2DM patients with CHD. The current study was, therefore, performed to evaluate the effects of vitamin $\mathrm{D}, \mathrm{K}$ and $\mathrm{Ca}$ co-administration on CIMT, glycaemic control, lipid concentrations, biomarkers of inflammation and oxidative stress in these patients.

\section{Methods}

\section{Participants}

This study was a randomised, double-blind, placebo-controlled trial that was registered in the Iranian registry of clinical trials (http://www.irct.ir: IRCT201506185623N45) and was carried out at a cardiology clinic affiliated to Kashan University of Medical Sciences (KUMS), Kashan, Iran, between June and September 2015. Inclusion criteria were as follows: overweight patients (BMI $\geq 25 \mathrm{~kg} / \mathrm{m}^{2}$ ) with T2DM, aged $40-85$ years with a CHD condition. According to criteria of the American Diabetes Association $^{(15)}$, patients who have one out of three of the following criteria were diagnosed with T2DM: fasting plasma glucose $(\mathrm{FPG}) \geq 126 \mathrm{mg} / \mathrm{dl}$, blood glucose 2 -h postprandial $\geq 200 \mathrm{mg} / \mathrm{dl}$ or glycated $\mathrm{Hb}(\mathrm{HbA} 1 \mathrm{C}) \geq 6.5 \%$. In addition, patients who had one or more of the following criteria were considered as having CHD: record of myocardial infarction, document of at least $50 \%$ stenosis in one or more coronary vessels upon cardiac catheterisation evaluated by angiography, document of exercise-induced ischaemia by treadmill electrocardiogram or nuclear perfusion stress imaging and a history of coronary re-vascularisation ${ }^{(16)}$. Exclusion criteria were consumption of vitamin $\mathrm{D}, \mathrm{K}$ and $\mathrm{Ca}$ supplements within the last 3 months, occurrence of an acute myocardial infarction within the past 3 months, a cardiac surgery within the past 3 months and major renal or liver failure.

\section{Ethics statements}

This study was performed according to the principles of the Declaration of Helsinki, and the study protocol was approved by the ethics committee of KUMS (reference no: IR.Kaums.
REC.1394.32). All patients were informed about the aims and protocol of the study, and written informed consent was obtained from all the participants.

\section{Study design}

At the onset of the study, patients were first matched one by one according to age, BMI, sex and the dosage and kind of medications used. Next, the matched patients were randomly assigned to the intervention and placebo groups. Subsequently, the participants were randomly allocated into two treatment groups. Group A (intervention; fifteen females and eighteen males: $n$ 33) received $5 \mu \mathrm{g}$ of vitamin $\mathrm{D}$ and $90 \mu \mathrm{g}$ of vitamin $\mathrm{K}_{2}$ to form MK-7 and $500 \mathrm{mg}$ Ca supplements as a tablet and group B (placebo; sixteen females and seventeen males: $n$ 33) received daily placebo tablets for 12 weeks. Owing to lack of information about the appropriate dosage of vitamin $\mathrm{D}, \mathrm{K}$ and $\mathrm{Ca}$ for overweight diabetic patients with $\mathrm{CHD}$, we used the above-mentioned doses of vitamin D plus Ca based on a previous study in postmenopausal women ${ }^{(17)}$ and a dose of vitamin $\mathrm{K}$ based on a previous study in older women and men $^{(12)}$. Vitamin D, K and Ca supplements and the placebos (cellulose) were manufactured by Aryan Salamat Pharmaceutical Company and Barij Essence Pharmaceutical Company, respectively. Both vitamin $\mathrm{D}, \mathrm{K}$ and $\mathrm{Ca}$ supplements and placebo tablets had similar packaging, and patients and researchers were not aware of the contents of the package until the end of study. Randomisation and allocation were blinded from researchers and subjects until the main analyses were completed. At the cardiology clinic, a trained nutritionist carried out the randomised allocation sequence and enrolment and assignment of the patients to the groups. At the beginning of the study, patients were requested to maintain their regular diet and levels of physical activity throughout the trial period. Compliance to the consumption of supplements and placebos was examined by checking the containers of the tablets as well as by measuring serum 25-hydroxyvitamin D (25(OH)D) levels. All participants completed three dietary records (2 weekdays and 1 weekend day) at week 2, 5, 8 and 11 of the trial. To obtain nutrient intakes of patients according to 3 -d food records, we applied Nutritionist IV software (First Databank) adopted for the Iranian food pattern. In the present study, physical activity was described as metabolic equivalents (MET) in hours per day. To determine the MET for each patient, we multiplied the times $(\mathrm{h} / \mathrm{d})$ reported for each physical activity by the related MET coefficient using standard tables ${ }^{(18)}$.

\section{Assessment of anthropometric measures}

In the present study, weight and height (Seca) were quantified at the beginning of the study and after intervention without shoes in minimal clothing in the cardiology clinic by a trained nutritionist. BMI was calculated as weight in $\mathrm{kg}$ divided by height in metres squared.

\section{Assessment of outcomes}

In the present study, we considered CIMT as the primary outcome and parameters of glucose homoeostasis, lipid profiles, 
biomarkers of inflammation and oxidative stress as secondary outcomes. Measurement of the CIMT was performed in patients at the 2-cm distance of the common carotid bifurcation, by the same sonographist, at study baseline and after 12 weeks of intervention using a Doppler ultrasonography device (Samsung Medison V20) with linear multifrequencies of $7 \cdot 5-10-\mathrm{MHz}$ probe. The physician was blinded to any clinical information of the subjects. The examinations were conducted in a quiet room with a controlled temperature of $21 \pm 2^{\circ} \mathrm{C}$. The measurements were made at the same time of the day to avoid diurnal variations and after a 10-15-min supine rest to stabilise blood pressure levels. Participants were requested to refrain from smoking and consumption of tea, caffeinated drinks or any foods for at least $10-12 \mathrm{~h}$ before the examination.

Fasting blood samples $(10 \mathrm{ml})$ were collected at the beginning and at the end of the study at Kashan Reference Laboratory in fasting conditions and centrifuged to separate serum. Next, the samples were stored at $-80^{\circ} \mathrm{C}$ before analysis. Serum $25(\mathrm{OH}) \mathrm{D}$ concentrations were quantified using a commercial ELISA kit (IDS) with inter- and intra-assay CV of $4.3-6.5 \%$, respectively. Serum insulin concentrations were assessed using an available ELISA kit (DiaMetra) with intra- and interassay CV of 2.8 and $4.9 \%$, respectively. The homoeostasis model for assessment of insulin resistance (HOMA-IR), $\beta$-cell function (HOMA-B) and the quantitative insulin sensitivity check index (QUICKI) were determined according to the suggested formulae ${ }^{(19)}$. Enzymatic kits (Pars Azmun) were used to quantify Ca, FPG, serum TAG and VLDL-, total-, LDL- and HDL-cholesterol concentrations. All inter- and intra-assay CV for $\mathrm{Ca}$, FPG and lipid concentrations were $<5 \%$. Serum high-sensitivity C-reactive protein (hs-CRP) concentrations were evaluated using a commercial ELISA kit (LDN) with intra- and inter-assay CV of 2.7 and $4.8 \%$, respectively. The plasma nitric oxide (NO) concentrations were assessed using the Griess method ${ }^{(20)}$. Plasma total antioxidant capacity (TAC) concentrations were determined by the ferric reducing antioxidant power method developed by Benzie \& Strain ${ }^{(21)}$, total GSH levels were determined using the method of Beutler \& Gelbart ${ }^{(22)}$ and malondialdehyde (MDA) concentrations were determined by the thiobarbituric acid reactive substances spectrophotometric test ${ }^{(23)}$. All inter- and intra-assay $\mathrm{CV}$ for NO, TAC, GSH and MDA concentrations were $<5 \%$. Measurements of vitamin D, Ca, FPG, insulin, lipid concentrations, biomarkers of inflammation and oxidative stress were conducted in a blinded manner, in duplicate, in pairs (pre/ post-intervention) at the same time, in the same analytical run and in random order to reduce systematic error and inter-assay variability.

\section{Statistical methods}

In the present study, we used a randomised clinical trial sample size calculation formula where type-one $(\alpha)$ and typetwo errors $(\beta)$ were 0.05 and 0.20 (power $=80 \%$ ), respectively. According to the previous trial ${ }^{(8)}$, we used $0.06 \mathrm{~mm}$ as $\mathrm{SD}$ and $0.05 \mathrm{~mm}$ as the change in mean $(d)$ of CIMT as a main variable; based on the formula, we needed twenty-six patients in each group. After considering seven dropouts in each group, the final sample size was thirty-three patients in each group.

To determine the normal distribution of the variables, we applied the Kolmogrov-Smirnov test. The intention-to-treat (ITT) analysis of the primary study end point was applied for all of the randomly allocated participants. To detect differences in the general characteristics and daily dietary macronutrient and micronutrient intakes between the two groups, independent samples Student's $t$ test was used. To identify within-group differences (pre- and post-intervention), we used paired samples $t$ tests. To determine the effects of vitamin $\mathrm{D}, \mathrm{K}$ and $\mathrm{Ca}$ co-administration on CIMT, glycaemic control, lipid profiles, biomarkers of inflammation and oxidative stress, we used oneway repeated-measures ANOVA. All the findings and $P$-values were based on Bonferroni's correction for pairwise comparisons. To evaluate for several confounders, we adjusted all analyses for baseline values of biochemical variables, age and baseline BMI to avoid potential bias. A $P$-value lower than 0.05 was considered significant. All statistical analyses were performed using Statistical Package for Social Science version 18 (SPSS Inc.).

\section{Results}

In the present study, three participants each from the vitamin D, K and $\mathrm{Ca}$ supplements group and the placebo group discontinued from the study because of personal reasons (Fig.1). However, all sixty-six participants were included in the final analysis using ITT principle. Overall, the compliance rate was high, such that higher than $90 \%$ of tablets were consumed throughout the study in both groups.

Mean duration of DM, consumption of antidiabetic and antilipidaemic drugs, and hypertension rate of the study participants were not statistically different between the two groups (data not shown). There were no significant differences between the two groups in terms mean age, height, baseline weight, baseline BMI and mean changes in weight and BMI during the trial (Table 1).

On the basis of the 3-d dietary records obtained throughout the intervention, we observed no significant change in dietary macronutrient and micronutrient intakes, including energy, carbohydrate, protein, fat, SFA, PUFA, MUFA, cholesterol, total dietary fibre, $\mathrm{Ca}, \mathrm{Mg}, \mathrm{Mn}, \mathrm{Zn}$ and vitamins $\mathrm{D}$ and $\mathrm{K}$ between the two groups (Table 2).

After 12 weeks of intervention, vitamin $\mathrm{D}, \mathrm{K}$ and $\mathrm{Ca}$ co-supplementation resulted in a significant reduction in maximum levels of left CIMT ( -0.04 (SD 0.22) $v$. +0.04 (SD 0.09) mm, $P=0.02$ ); however, it did not influence mean levels of left and right CIMT and maximum levels of right CIMT compared with the placebo group (Table 3 ). In addition, changes in serum vitamin $\mathrm{D}(+6.5(\mathrm{sD} 7 \cdot 8) v .+0 \cdot 4(\mathrm{sD} 2 \cdot 2) \mathrm{ng} / \mathrm{ml}, P<0 \cdot 001)$, Ca $(+0 \cdot 6(\mathrm{sD} 0 \cdot 3) v \cdot+0 \cdot 1 \quad(\mathrm{sD} 0 \cdot 1) \mathrm{mg} / \mathrm{dl}, P<0 \cdot 001)$ and insulin concentrations $(-0 \cdot 9(\mathrm{sD} 3 \cdot 1) v .+2 \cdot 6(\mathrm{sD} 7 \cdot 2) \mu \mathrm{IU} / \mathrm{ml}, P=0 \cdot 01)$, HOMA-IR ( -0.4 (sD 1.2) $v .+0 \cdot 7$ (sD 2.3), $P=0 \cdot 01$ ), HOMA-B $(-2 \cdot 1$ (sD 9.0) $v .+8.9($ sD 23.7),$P=0.01)$ and the QUICKI $(+0.007$ (sD 0.01) $v .-0.006$ (sD 0.02), $P=0.01$ ) in supplemented patients were significantly different from those in patients in the placebo group. Supplementation resulted in significant changes in 


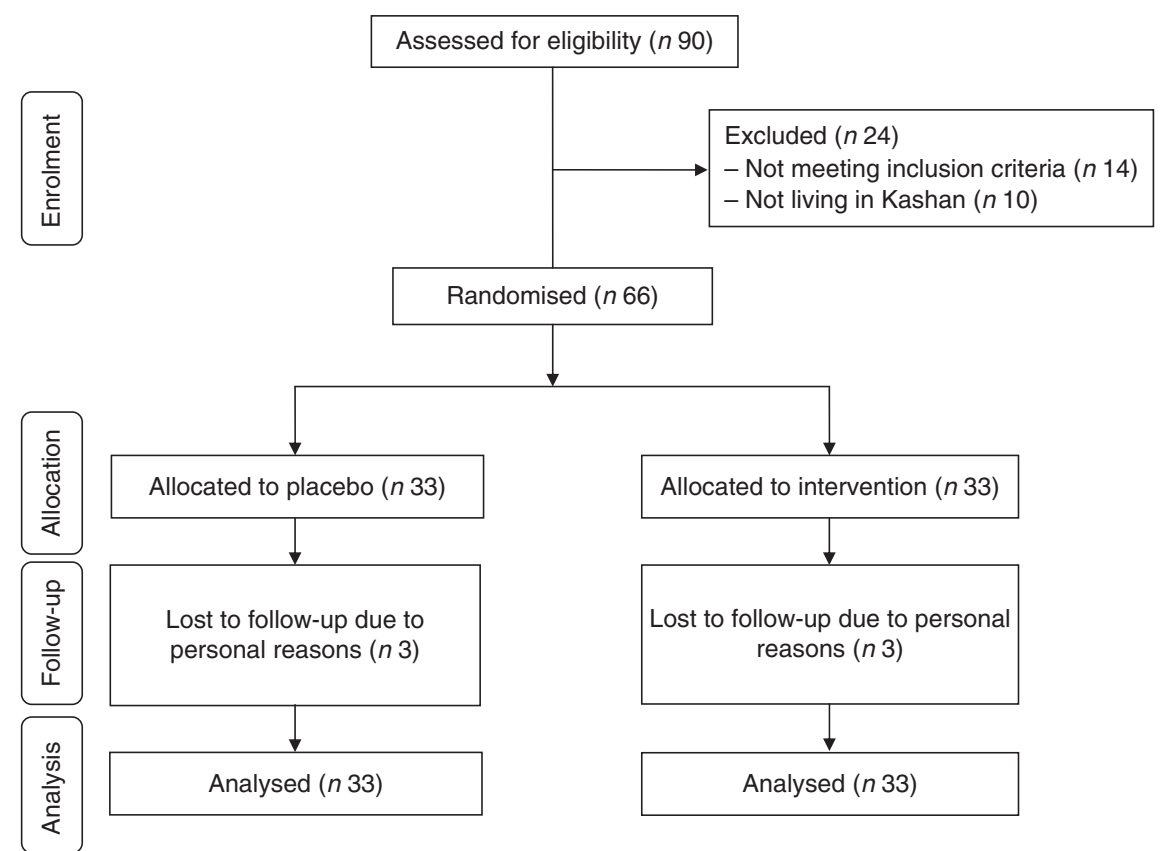

Fig. 1. Summary of patient flow diagram.

Table 1. General characteristics of the study participants (Mean values and standard deviations)

\begin{tabular}{|c|c|c|c|c|c|}
\hline & \multicolumn{2}{|c|}{$\begin{array}{l}\text { Placebo group } \\
\quad(n 33) \\
\end{array}$} & \multicolumn{2}{|c|}{$\begin{array}{l}\text { Vitamin } \mathrm{D}, \mathrm{K} \text { and } \\
\text { Ca group }(n 33)\end{array}$} & \multirow[b]{2}{*}{$P^{*}$} \\
\hline & Mean & SD & Mean & SD & \\
\hline Age (years) & 65.0 & $11 \cdot 1$ & 65.9 & 11.4 & 0.75 \\
\hline Height $(\mathrm{cm})$ & $158 \cdot 1$ & $10 \cdot 3$ & $160 \cdot 2$ & 11.3 & 0.44 \\
\hline Weight at study baseline (kg) & $74 \cdot 1$ & $12 \cdot 9$ & $76 \cdot 1$ & $14 \cdot 8$ & 0.54 \\
\hline Weight at end of trial $(\mathrm{kg})$ & 74.6 & $13 \cdot 1$ & $76 \cdot 6$ & $15 \cdot 5$ & 0.57 \\
\hline Weight change (kg) & 0.5 & 1.5 & 0.5 & $2 \cdot 4$ & 0.90 \\
\hline BMI at study baseline $\left(\mathrm{kg} / \mathrm{m}^{2}\right)$ & 29.6 & 4.3 & 29.7 & $5 \cdot 2$ & 0.96 \\
\hline $\mathrm{BMI}$ at end of trial $\left(\mathrm{kg} / \mathrm{m}^{2}\right)$ & 29.8 & 4.4 & 29.9 & $5 \cdot 6$ & 0.97 \\
\hline BMl change $\left(\mathrm{kg} / \mathrm{m}^{2}\right)$ & 0.2 & 0.6 & 0.2 & 1.0 & 0.90 \\
\hline MET-h/d at study baseline & $26 \cdot 6$ & $2 \cdot 1$ & $27 \cdot 3$ & $2 \cdot 2$ & $0 \cdot 18$ \\
\hline MET-h/d at end of trial & 26.5 & $2 \cdot 2$ & 27.4 & $2 \cdot 3$ & 0.12 \\
\hline MET-h/d change & -0.1 & 0.7 & 0.1 & 0.7 & 0.38 \\
\hline
\end{tabular}

MET, metabolic equivalents.

* Obtained from independent $t$ test.

serum HDL-cholesterol (+2.7 (sD 7.0) v. -2.5 (sD 5.7) $\mathrm{mg} / \mathrm{dl}$, $P=0 \cdot 002)$, hs-CRP $(-1320 \cdot 1$ (sD 3758.3) v. $+464 \cdot 0$ (sD 3053.3) ng/ $\mathrm{ml}, P=0.03)$ and plasma MDA concentrations ( -0.4 (SD 0.5$) v$. -1.0 (sD 1.1) $\mu \mathrm{mol} / 1, \quad P=0.007$ ) compared with the placebo group. We did not observe any significant differences in changes in other lipid concentrations and biomarkers of oxidative stress when comparing the two groups.

There was a significant difference in the baseline levels of biochemical variables, $\mathrm{Ca}$, insulin, total cholesterol, HDL-cholesterol, NO, TAC and MDA between the two groups; however, additional adjustments for these variables did not influence the results except for findings on HDL-cholesterol $(P=0.07)$ and MDA $(P=0.36)$ (Table 4). Similarly, further adjustments for age and baseline BMI did not influence our findings.
Table 2. Dietary intakes of study participants throughout the study (Mean values and standard deviations)

\begin{tabular}{|c|c|c|c|c|c|}
\hline & \multicolumn{2}{|c|}{$\begin{array}{l}\text { Placebo group } \\
\quad(n 33)\end{array}$} & \multicolumn{2}{|c|}{$\begin{array}{l}\text { Vitamin } \mathrm{D}, \mathrm{K} \text { and } \\
\text { Ca group ( } n \text { 33) }\end{array}$} & \multirow[b]{2}{*}{$P^{*}$} \\
\hline & Mean & SD & Mean & SD & \\
\hline Energy $(\mathrm{kJ} / \mathrm{d})$ & 8389 & 414 & 8456 & 297 & 0.48 \\
\hline Energy $(\mathrm{kcal} / \mathrm{d})$ & 2005 & 99 & 2021 & 71 & 0.48 \\
\hline Carbohydrates $(\mathrm{g} / \mathrm{d})$ & 289.5 & $24 \cdot 7$ & $296 \cdot 1$ & 20.2 & 0.26 \\
\hline Protein $(\mathrm{g} / \mathrm{d})$ & $79 \cdot 7$ & $10 \cdot 4$ & 78.6 & 4.4 & 0.58 \\
\hline Fat $(\mathrm{g} / \mathrm{d})$ & 61.7 & 7.0 & 61.5 & 6.9 & 0.89 \\
\hline SFA $(g / d)$ & $15 \cdot 9$ & $3 \cdot 1$ & $16 \cdot 4$ & $2 \cdot 1$ & 0.47 \\
\hline PUFA $(g / d)$ & $24 \cdot 4$ & 5.7 & $23 \cdot 8$ & 5.8 & 0.70 \\
\hline MUFA $(\mathrm{g} / \mathrm{d})$ & $15 \cdot 0$ & 3.0 & $15 \cdot 1$ & $2 \cdot 4$ & 0.86 \\
\hline Cholesterol $(\mathrm{mg} / \mathrm{d})$ & $142 \cdot 1$ & $34 \cdot 1$ & 134.9 & $21 \cdot 7$ & 0.34 \\
\hline $\operatorname{TDF}(\mathrm{g} / \mathrm{d})$ & $15 \cdot 6$ & $3 \cdot 3$ & $16 \cdot 9$ & 3.8 & 0.17 \\
\hline$M g(\mathrm{mg} / \mathrm{d})$ & 241.7 & 39.1 & 256.9 & 34.1 & 0.11 \\
\hline $\mathrm{Ca}(\mathrm{mg} / \mathrm{d})$ & $1136 \cdot 9$ & 74.6 & $1154 \cdot 4$ & $108 \cdot 0$ & 0.38 \\
\hline Vitamin D $(\mu \mathrm{g} / \mathrm{d})$ & 1.4 & 0.5 & 1.4 & 0.6 & 0.93 \\
\hline Vitamin $K(\mu \mathrm{g} / \mathrm{d})$ & $66 \cdot 7$ & $25 \cdot 8$ & 73.2 & 23.9 & 0.31 \\
\hline
\end{tabular}

TDF, total dietary fibre.

* Obtained from independent $t$ test.

\section{Discussion}

In the present study, which to the best of our knowledge is the first of its kind, we demonstrated that vitamin D, K and Ca co-supplementation for 12 weeks among these patients had beneficial effects on maximum levels of left CIMT, glycaemic control, HDL-cholesterol, hs-CRP and MDA levels; however, it did not have any effect on other lipid profiles and biomarkers of oxidative stress.

We found that vitamin $\mathrm{D}, \mathrm{K}$ and $\mathrm{Ca}$ co-supplementation resulted in a significant reduction in maximum levels of left CIMT; however, it did not influence mean levels of left and right CIMT and maximum levels of right CIMT compared with the 
Table 3. Carotid intima-media thickness (CIMT), metabolic profiles, biomarkers of inflammation and oxidative stress at baseline and 12 weeks after the intervention in patients with type 2 diabetes mellitus, overweight and $\mathrm{CHD}$

(Mean values and standard deviations)

\begin{tabular}{|c|c|c|c|c|c|c|c|c|c|c|c|c|c|c|c|}
\hline & \multicolumn{7}{|c|}{ Placebo group ( $n$ 33) } & \multicolumn{7}{|c|}{ Vitamin $\mathrm{D}, \mathrm{K}$ and Ca group ( $n$ 33) } & \multirow[b]{3}{*}{$P+$} \\
\hline & \multicolumn{2}{|c|}{ Baseline } & \multicolumn{2}{|c|}{ End of trial } & \multicolumn{2}{|c|}{ Change } & \multirow[b]{2}{*}{$P^{*}$} & \multicolumn{2}{|c|}{ Baseline } & \multicolumn{2}{|c|}{ End of trial } & \multicolumn{2}{|c|}{ Change } & \multirow[b]{2}{*}{$P^{*}$} & \\
\hline & Mean & SD & Mean & SD & Mean & SD & & Mean & SD & Mean & SD & Mean & SD & & \\
\hline Mean left CIMT (mm) & 0.73 & 0.17 & 0.74 & $0 \cdot 17$ & 0.01 & 0.07 & 0.43 & 0.69 & $0 \cdot 13$ & 0.69 & $0 \cdot 11$ & 0.0009 & 0.10 & 0.96 & 0.67 \\
\hline Maximum left CIMT (mm) & 0.84 & 0.20 & 0.88 & 0.18 & 0.04 & 0.09 & 0.24 & 0.86 & 0.23 & 0.80 & 0.11 & -0.04 & 0.22 & 0.78 & 0.02 \\
\hline Mean right CIMT (mm) & 0.68 & 0.11 & 0.69 & 0.11 & 0.005 & 0.08 & 0.70 & 0.62 & 0.13 & 0.63 & 0.12 & 0.008 & 0.09 & 0.61 & 0.90 \\
\hline Maximum right CIMT (mm) & 0.77 & 0.13 & 0.79 & 0.13 & 0.02 & 0.11 & 0.24 & 0.76 & $0 \cdot 16$ & 0.75 & 0.15 & -0.008 & 0.16 & 0.78 & 0.36 \\
\hline Vitamin D $(\mathrm{ng} / \mathrm{ml})$ & 13.0 & $6 \cdot 3$ & 13.4 & 6.5 & 0.4 & 2.2 & 0.28 & $15 \cdot 0$ & 8.6 & 21.4 & 7.3 & 6.5 & 7.8 & $<0.001$ & $<0.001$ \\
\hline $\mathrm{Ca}(\mathrm{mg} / \mathrm{dl})$ & 8.5 & 0.4 & 8.6 & 0.4 & 0.1 & 0.1 & 0.009 & 8.2 & 0.7 & 8.8 & 0.7 & 0.6 & 0.3 & $<0.001$ & $<0.001$ \\
\hline $\mathrm{FPG}(\mathrm{mg} / \mathrm{dl})$ & $122 \cdot 2$ & $46 \cdot 9$ & $145 \cdot 5$ & 70.4 & $23 \cdot 3$ & $67 \cdot 3$ & 0.05 & 134.9 & 49.7 & $140 \cdot 7$ & $56 \cdot 2$ & $5 \cdot 8$ & $35 \cdot 6$ & 0.35 & 0.19 \\
\hline Insulin $(\mu \mathrm{lU} / \mathrm{ml})$ & 17.5 & $8 \cdot 3$ & 20.1 & 10.5 & 2.6 & 7.2 & 0.04 & 13.6 & 6.8 & 12.7 & 7.2 & -0.9 & 3.1 & 0.08 & 0.01 \\
\hline HOMA-IR & $5 \cdot 3$ & 3.5 & 6.0 & 3.9 & 0.7 & $2 \cdot 3$ & 0.07 & 4.4 & $2 \cdot 4$ & 4.0 & 2.4 & -0.4 & 1.2 & 0.09 & 0.01 \\
\hline HOMA-B & $55 \cdot 6$ & 39.6 & 64.5 & $47 \cdot 2$ & 8.9 & 23.7 & 0.03 & 38.7 & $28 \cdot 1$ & $36 \cdot 6$ & $30 \cdot 1$ & $-2 \cdot 1$ & 9.0 & 0.17 & 0.01 \\
\hline QUICKI & 0.31 & 0.03 & 0.30 & 0.02 & -0.006 & 0.02 & 0.21 & 0.31 & 0.02 & 0.32 & 0.03 & 0.007 & 0.01 & 0.05 & 0.01 \\
\hline TAG (mg/dl) & 114.3 & 53.3 & $139 \cdot 2$ & $58 \cdot 2$ & 24.9 & $50 \cdot 2$ & 0.007 & $110 \cdot 1$ & 48.6 & $132 \cdot 3$ & 41.6 & $22 \cdot 2$ & 31.9 & $<0.001$ & 0.78 \\
\hline VLDL-cholesterol (mg/dl) & $22 \cdot 9$ & $10 \cdot 7$ & 27.9 & 11.6 & $5 \cdot 0$ & $10 \cdot 1$ & 0.007 & $22 \cdot 0$ & 9.7 & $26 \cdot 5$ & 8.3 & 4.4 & 6.4 & $<0.001$ & 0.78 \\
\hline Total cholesterol $(\mathrm{mg} / \mathrm{dl})$ & 141.4 & $32 \cdot 0$ & 144.3 & $28 \cdot 1$ & 2.9 & 29.5 & 0.58 & 122.4 & $35 \cdot 6$ & $138 \cdot 3$ & 28.5 & $15 \cdot 9$ & 27.4 & 0.002 & 0.06 \\
\hline LDL-cholesterol $(\mathrm{mg} / \mathrm{dl})$ & $72 \cdot 2$ & $25 \cdot 3$ & 72.6 & $22 \cdot 1$ & 0.4 & 21.6 & 0.92 & 59.9 & $25 \cdot 0$ & 68.9 & 24.6 & 8.8 & 19.9 & 0.01 & 0.10 \\
\hline HDL-cholesterol (mg/dl) & $46 \cdot 3$ & $7 \cdot 7$ & 43.8 & 6.4 & -2.5 & $5 \cdot 7$ & 0.01 & 40.5 & 8.9 & 43.2 & $6 \cdot 6$ & $2 \cdot 7$ & 7.0 & 0.03 & 0.002 \\
\hline Total cholesterol:HDL-cholesterol ratio & 3.1 & 0.7 & 3.3 & 0.7 & 0.2 & 0.5 & 0.02 & 3.0 & 0.6 & 3.2 & 0.6 & 0.2 & 0.4 & 0.009 & 0.81 \\
\hline hs-CRP (ng/ml) & $5860 \cdot 8$ & 5244.5 & 6324.8 & $5880 \cdot 9$ & 464.0 & $3053 \cdot 3$ & 0.38 & 4021.9 & $4040 \cdot 8$ & 2701.9 & 2332.1 & $-1320 \cdot 1$ & 3758.3 & 0.05 & 0.03 \\
\hline NO $(\mu \mathrm{mol} / \mathrm{l})$ & $62 \cdot 7$ & 11.3 & $56 \cdot 7$ & 10.9 & -6.1 & 12.5 & 0.009 & 51.8 & 9.5 & 50.4 & $11 \cdot 7$ & -1.4 & 7.6 & 0.29 & 0.07 \\
\hline $\mathrm{TAC}(\mathrm{mmol} / \mathrm{l})$ & 1063.5 & 228.9 & 1062.9 & 329.1 & -0.6 & 400.4 & 0.99 & 951.5 & $180 \cdot 3$ & $1032 \cdot 8$ & 165.5 & $81 \cdot 3$ & 141.4 & 0.002 & 0.27 \\
\hline $\mathrm{GSH}(u \mathrm{~mol} / \mathrm{l})$ & 533.5 & 61.3 & 588.6 & 87.0 & 55.0 & 88.8 & 0.001 & 536.8 & 81.2 & 631.5 & 152.5 & 94.6 & 136.1 & $<0.001$ & 0.16 \\
\hline $\mathrm{MDA}(\mu \mathrm{mol} / \mathrm{l})$ & 3.4 & 0.5 & 3.0 & 0.5 & -0.4 & 0.5 & $<0.001$ & 3.9 & 0.8 & 2.9 & 0.7 & -1.0 & $1 \cdot 1$ & $<0.001$ & 0.007 \\
\hline
\end{tabular}

FPG, fasting plasma glucose; HOMA-IR, homoeostasis model for assessment of estimated insulin resistance; HOMA-B, homoeostasis model for assessment of estimated $\beta$ cell function; QUICKI, quantitative insulin sensitivity check index; hs-CRP, high-sensitivity C-reactive protein; NO, nitric oxide; TAC, total antioxidant capacity; MDA, malondialdehyde.
hes

$P$ values represent the timexproup interaction (computed by analysis of the one-way repeated-measures ANOVA). 
Table 4. Adjusted changes in metabolic variables in patients with type 2 diabetes mellitus, overweight and CHD* (Mean values with their standard errors)

\begin{tabular}{|c|c|c|c|c|c|}
\hline & \multicolumn{2}{|c|}{ Placebo group ( $n$ 33) } & \multicolumn{2}{|c|}{ Vitamin $\mathrm{D}, \mathrm{K}$ and Ca group ( $n$ 33) } & \multirow[b]{2}{*}{$P \dagger$} \\
\hline & Mean & SE & Mean & $\mathrm{SE}$ & \\
\hline Mean left CIMT (mm) & 0.01 & 0.01 & -0.005 & 0.01 & 0.33 \\
\hline Maximum left CIMT (mm) & 0.03 & 0.02 & -0.04 & 0.02 & 0.005 \\
\hline Mean right CIMT (mm) & 0.01 & 0.01 & -0.004 & 0.01 & 0.28 \\
\hline Maximum right CIMT (mm) & 0.02 & 0.01 & -0.01 & 0.01 & 0.13 \\
\hline Vitamin D $(\mathrm{ng} / \mathrm{ml})$ & 0.1 & 0.9 & $6 \cdot 8$ & 0.9 & $<0.001$ \\
\hline $\mathrm{Ca}(\mathrm{mg} / \mathrm{dl})$ & $0 \cdot 1$ & 0.03 & 0.6 & 0.03 & $<0.001$ \\
\hline $\mathrm{FPG}(\mathrm{mg} / \mathrm{dl})$ & $22 \cdot 1$ & $9 \cdot 3$ & $7 \cdot 1$ & 9.3 & 0.25 \\
\hline Insulin $(\mu \mathrm{lU} / \mathrm{ml})$ & $2 \cdot 7$ & 1.0 & $-1 \cdot 2$ & 1.0 & 0.009 \\
\hline HOMA-IR & 0.8 & 0.4 & -0.4 & 0.4 & 0.01 \\
\hline HOMA-B & $8 \cdot 7$ & $3 \cdot 2$ & -1.9 & $3 \cdot 2$ & 0.02 \\
\hline QUICKI & -0.008 & 0.004 & 0.008 & 0.004 & 0.005 \\
\hline TAG (mg/dl) & $25 \cdot 7$ & 6.5 & 21.5 & 6.5 & 0.65 \\
\hline VLDL-cholesterol $(\mathrm{mg} / \mathrm{dl})$ & $5 \cdot 1$ & 1.3 & 4.3 & 1.3 & 0.65 \\
\hline Total cholesterol (mg/dl) & $7 \cdot 7$ & $4 \cdot 1$ & $11 \cdot 1$ & $4 \cdot 1$ & 0.56 \\
\hline LDL-cholesterol (mg/dl) & $2 \cdot 8$ & 3.2 & $6 \cdot 3$ & 3.2 & 0.44 \\
\hline HDL-cholesterol (mg/dl) & $-1 \cdot 0$ & 0.9 & 1.2 & 0.9 & 0.08 \\
\hline Total cholesterol:HDL-cholesterol ratio & 0.2 & 0.1 & 0.2 & 0.1 & 0.68 \\
\hline hs-CRP (ng/ml) & 764.8 & 556.7 & $-1620 \cdot 3$ & 556.7 & 0.004 \\
\hline $\mathrm{NO}(\mu \mathrm{mol} / \mathrm{l})$ & -3.9 & 1.8 & -3.6 & $1 \cdot 8$ & 0.91 \\
\hline $\mathrm{TAC}(\mathrm{mmol} / \mathrm{l})$ & 43.5 & $46 \cdot 6$ & 37.3 & $46 \cdot 7$ & 0.92 \\
\hline GSH $(\mu \mathrm{mol} / \mathrm{l})$ & $54 \cdot 7$ & $19 \cdot 8$ & $95 \cdot 0$ & $19 \cdot 8$ & 0.15 \\
\hline MDA ( $\mu \mathrm{mol} / \mathrm{l})$ & -0.6 & 0.1 & -0.8 & 0.1 & 0.40 \\
\hline
\end{tabular}

CIMT, carotid intima-media thickness; FPG, fasting plasma glucose; HOMA-IR, homoeostasis model for assessment of estimated insulin resistance; HOMA-B, homoeostasis model for assessment of estimated $\beta$ cell function; QUICKI, quantitative insulin sensitivity check index; hs-CRP, high-sensitivity C-reactive protein; NO, nitric oxide; TAC, total antioxidant capacity; MDA, malondialdehyde.

* Values are adjusted for baseline values, age and BMI at baseline.

$\dagger$ Obtained from ANCOVA.

placebo. Previous studies have shown that there is a difference between the left and right CIMT. It was speculated that haemodynamics status, age, sex, metabolic profiles especially lipid concentrations, blood glucose levels and other risk factors would result in different effects on the left and right CIMT $^{(24)}$. In a study by Luo et al. ${ }^{(24)}$, left CIMT correlated better with blood biochemical indices such as total cholesterol, LDL-cholesterol and blood glucose levels. In the present study, decreased biomarkers of inflammation and lipid peroxidation in the intervention group may have resulted in decreased maximum levels of left CIMT. Hileman et al. ${ }^{(25)}$ demonstrated that decreased markers of oxidative stress, inflammation and monocyte activation resulted in improved CIMT. Furthermore, the effect of vitamin $\mathrm{D}, \mathrm{K}$ and $\mathrm{Ca}$ co-supplementation on maximum levels of left CIMT could be a chance finding. We did not observe any significant effect of vitamin D, K and Ca co-supplementation on mean levels of left and right CIMT. This might be explained by the normal levels of CIMT in the study population ( $85 \%$ in the placebo group and $82 \%$ in the intervention group). A few studies have evaluated the association between vitamin $\mathrm{D}$ levels and CIMT. In a study by Choi et $a l^{(26)}$, it was observed that there is a negative relation between vitamin D levels and CIMT in HIV-infected persons. In addition, vitamin D and $\mathrm{K}$ supplementation among postmenopausal women for 3 years did not influence CIMT, but affected elastic properties of the arterial vessel wall ${ }^{(8)}$. However, there was no direct association between serum 25(OH)D and CIMT in HIV-infected youth ${ }^{(27)}$. Vitamin $\mathrm{K}$ intake may affect CIMT through the effect on the post-translational processing of matrix Gla-protein $(\mathrm{MGP})^{(8)}$, which is synthesised in a number of non-hepatic tissues, notably cartilage and the arterial vessel wall and is regarded as a major inhibitor of soft tissue calcification ${ }^{(28)}$. In addition, vitamin D has a role in the regulation of MGP gene expression, which may support the control of CIMT. In a study by Fraser \& Price ${ }^{(29)}$, it was indicated that the MGP promotor contains a vitamin D response element that is responsible for a 2-3-fold enhancement of MGP expression after vitamin D binding.

The present study demonstrated that combined vitamin $\mathrm{D}, \mathrm{K}$ and Ca supplementation in overweight patients with T2DM and CHD for 12 weeks was associated with a significant reduction in serum insulin, HOMA-IR and HOMA-B and a significant increase in QUICKI and serum HDL-cholesterol levels, but it did not affect FPG and other lipid profiles. Supporting our findings, Tabesh et al. ${ }^{(11)}$ demonstrated that an 8-week supplementation with joint $1000 \mathrm{mg} / \mathrm{d} \mathrm{Ca}$ and $1250 \mu \mathrm{g} /$ week vitamin D supplementation among patients with T2DM improved glycaemic control and lipid profiles. We have previously shown that $1000 \mathrm{mg} \mathrm{Ca} / \mathrm{d}$ and a $1250 \mu \mathrm{g}$ vitamin $\mathrm{D}_{3}$ twice during the study (at study baseline and on day 21 of the intervention) among patients with gestational diabetes mellitus resulted in improved parameters of glucose homoeostasis as well as LDL-cholesterol and HDL-cholesterol levels ${ }^{(10)}$. Furthermore, vitamin $\mathrm{K}$ supplementation for 36 months at a dosage of $500 \mu \mathrm{g} / \mathrm{d}$ decreased HOMA-IR among older men, but it did not affect older women ${ }^{(12)}$. Vitamin D and Ca supplementation may improve metabolic profiles through their effects on upregulation of the insulin receptor genes ${ }^{(30)}$ and the regulation of insulin secretion from the pancreatic $\beta$-cells ${ }^{(31)}$. Furthermore, 
previous studies have proposed that osteocalcin and vitamin $\mathrm{K}$ administration may improve insulin sensitivity through the enhancement of $\beta$-cell proliferation, adiponectin expression ${ }^{(32)}$ and suppression of inflammation ${ }^{(33)}$.

Our study showed that compared with placebo, vitamin D, K and $\mathrm{Ca}$ co-administration for 12 weeks decreased serum hs-CRP and plasma MDA concentrations, whereas it did not influence $\mathrm{NO}$ and other biomarkers of oxidative stress in overweight diabetic patients with CHD. Our previous study among patients with polycystic ovary syndrome has indicated that taking $\mathrm{Ca}$ plus vitamin $\mathrm{D}$ supplements for 8 weeks significantly decreased hs-CRP, MDA and increased TAC and GSH, whereas it did not affect NO levels ${ }^{(34)}$. In addition, joint vitamin $\mathrm{D}$ and $\mathrm{Ca}$ supplementation among patients with congestive heart failure for 14 weeks improved biomarkers of oxidative stress $^{(35)}$. However, taking $2 \mathrm{~g} / \mathrm{d}$ Ca plus $20 \mu \mathrm{g}$ vitamin $\mathrm{D}$ for 6 months had no significant effects on hs-CRP levels among patients with colorectal adenoma ${ }^{(36)}$. Less production of PTH after taking Ca and vitamin D supplements would result in decreased production of inflammatory cytokines $^{(37)}$, which in turn might explain the effects of $\mathrm{Ca}$ and vitamin D on hs-CRP. A decrease in reactive oxygen species and pro-inflammatory cytokines by vitamin D supplements might explain its favourable effects on oxidative stress ${ }^{(38)}$.

To interpret the findings of the present study, some limitations need to be considered. Owing to limited funding, we did not assess the effects of vitamin $\mathrm{D}, \mathrm{K}$ and $\mathrm{Ca}$ co-supplementation on vitamin $\mathrm{K}$ levels, osteocalcin or MGP and other inflammatory cytokines. We agreed that compliance and dispensability are related to elasticity, and that is the outcome mostly affected by vitamin $\mathrm{K}$; however, due to funding limitations, we did not evaluate vascular compliance and dispensability. In addition, the treatment effects observed in our study result from an indistinguishable component of the supplements. Therefore, further studies are needed with single supplements used in the present study in order to evaluate the beneficial effects on CIMT and metabolic status. In the present study, the sample size was also small. Furthermore, our study was relatively of short duration of intervention. Long-term interventions with bigger sample size might result in greater changes in the clinical end points. It must also be kept in mind that the beneficial effect seen in the present study by vitamin D, $\mathrm{K}$ and $\mathrm{Ca}$ co-supplementation might be explained by the fact that the mean serum $25(\mathrm{OH}) \mathrm{D}$ concentrations were low in both groups at baseline. Vitamin D, K and Ca supplementation has been hypothesised to act jointly rather than independently. Thus, a relatively low dose of cholecalciferol $(10 \mu \mathrm{g})$ and vitamin $\mathrm{K}(180 \mu \mathrm{g})$ that was effective in this population might not be in others with better status. As the study was carried out during summer (June through September), we did not expect to see a difference in serum vitamin D concentrations between the two groups. Furthermore, the study participants were elderly subjects who normally have limited physical activity levels and sun exposure than others.

Overall, vitamin $\mathrm{D}, \mathrm{K}$ and $\mathrm{Ca}$ co-supplementation for 12 weeks among diabetic patients with stable CHD had beneficial effects on maximum levels of left CIMT, glycaemic control, HDL-cholesterol, hs-CRP and MDA levels; however, it did not affect maximum levels of right CIMT, mean levels of left and right CIMT, other lipid profiles and biomarkers of oxidative stress. Furthermore, the effect of vitamin D, K and Ca co-supplementation on maximum levels of left CIMT could be a chance finding.

\section{Acknowledgements}

The present study was funded by a grant from the Vice-chancellor for Research, KUMS, Iran.

The study was supported by a grant from KUMS.

Z. A. and A. E. contributed to the conception, design, statistical analysis and drafting of the manuscript. F. R., F. B., Z. R., H. R. T., M. R., S. P., M. D. M., S. T. and A. A. M. contributed to the data collection process and manuscript drafting. A. E. supervised the study. All the authors approved the final version for submission.

The authors declare that there are no conflicts of interest.

\section{References}

1. Holper S, Nolte H, Bober E, et al. (2015) Dissection of metabolic pathways in the $\mathrm{Db} / \mathrm{Db}$ mouse model by integrative proteome and acetylome analysis. Mol Biosyst 11, 908-922.

2. Casella S, Bielli A, Mauriello A, et al. (2015) Molecular pathways regulating macrovascular pathology and vascular smooth muscle cells phenotype in type 2 diabetes. Int $\mathrm{J} \mathrm{Mol}$ Sci 16, 24353-24368.

3. Yapei Y, Xiaoyan R, Sha Z, et al. (2015) Clinical significance of arterial stiffness and thickness biomarkers in type 2 diabetes mellitus: an up-to-date meta-analysis. Med Sci Monit 21, $2467-2475$

4. Chua SK, Kilung A, Ong TK, et al. (2014) Carotid intima media thickness and high sensitivity C-reactive protein as markers of cardiovascular risk in a Malaysian population. Med J Malaysia 69, 166-174.

5. Kawasaki R, Cheung N, Islam FM, et al. (2011) Is diabetic retinopathy related to subclinical cardiovascular disease? Ophthalmology 118, 860-865.

6. Hamdy Al-Said N, Abd El Ghaffar Mohamed N, Salam RF, et al. (2015) Vitamin D as a risk factor for premature atherosclerosis in patients with type 2 diabetes. Ther Adv Endocrinol Metab $\mathbf{6}$, 249-257.

7. Petchey WG, Hickman IJ, Duncan E, et al. (2009) The role of 25-hydroxyvitamin D deficiency in promoting insulin resistance and inflammation in patients with chronic kidney disease: a randomised controlled trial. BMC Nephrol 10, 41.

8. Braam LA, Hoeks AP, Brouns F, et al. (2004) Beneficial effects of vitamins $\mathrm{D}$ and $\mathrm{K}$ on the elastic properties of the vessel wall in postmenopausal women: a follow-up study. Thromb Haemost 91, 373-380.

9. Kurnatowska I, Grzelak P, Masajtis-Zagajewska A, et al. (2015) Effect of vitamin $\mathrm{K}_{2}$ on progression of atherosclerosis and vascular calcification in nondialyzed patients with chronic kidney disease stages 3-5. Pol Arch Med Wewn 125, 631-640.

10. Asemi Z, Karamali M \& Esmaillzadeh A (2014) Effects of calciumvitamin D co-supplementation on glycaemic control, inflammation and oxidative stress in gestational diabetes: a randomised placebo-controlled trial. Diabetologia 57, 1798-1806.

11. Tabesh M, Azadbakht L, Faghihimani E, et al. (2014) Effects of calcium-vitamin D co-supplementation on metabolic profiles in vitamin $\mathrm{D}$ insufficient people with type 2 
diabetes: a randomised controlled clinical trial. Diabetologia 57, 2038-2047.

12. Yoshida M, Jacques PF, Meigs JB, et al. (2008) Effect of vitamin K supplementation on insulin resistance in older men and women. Diabetes Care 31, 2092-2096.

13. Nair-Shalliker V, Armstrong BK \& Fenech M (2012) Does vitamin D protect against DNA damage? Mutat Res $\mathbf{7 3 3}$ 50-57.

14. Zemel MB (2002) Regulation of adiposity and obesity risk by dietary calcium: mechanisms and implications. J Am Coll Nutr 21, 146S-151S

15. American Diabetes Association (2014) Diagnosis and classification of diabetes mellitus. Diabetes Care 37, Suppl. 1, S81-S90.

16. Welles CC, Whooley MA, Karumanchi SA, et al. (2014) Vitamin D deficiency and cardiovascular events in patients with coronary heart disease: data from the Heart and Soul Study. Am J Epidemiol 179, 1279-1287.

17. Schnatz PF, Jiang X, Vila-Wright S, et al. (2014) Calcium/ vitamin D supplementation, serum 25-hydroxyvitamin D concentrations, and cholesterol profiles in the women's health initiative calcium/vitamin D randomized trial. Menopause 21, 823-833.

18. Ainsworth BE, Haskell WL, Whitt MC, et al. (2000) Compendium of physical activities: an update of activity codes and MET intensities. Med Sci Sports Exerc 32, S498-S504.

19. Pisprasert V, Ingram KH, Lopez-Davila MF, et al. (2013) Limitations in the use of indices using glucose and insulin levels to predict insulin sensitivity: impact of race and gender and superiority of the indices derived from oral glucose tolerance test in African Americans. Diabetes Care 36, 845-853.

20. Tatsch E, Bochi GV, Pereira Rda S, et al. (2011) A simple and inexpensive automated technique for measurement of serum nitrite/nitrate. Clin Biochem 44, 348-350.

21. Benzie IF \& Strain JJ (1996) The ferric reducing ability of plasma (FRAP) as a measure of 'antioxidant power': the FRAP assay. Anal Biochem 239, 70-76.

22. Beutler E \& Gelbart T (1985) Plasma glutathione in health and in patients with malignant disease. I Lab Clin Med 105 , $581-584$

23. Janero DR (1990) Malondialdehyde and thiobarbituric acid-reactivity as diagnostic indices of lipid peroxidation and peroxidative tissue injury. Free Radic Biol Med 9, 515-540.

24. Luo X, Yang Y, Cao T, et al. (2011) Differences in left and right carotid intima-media thickness and the associated risk factors. Clin Radiol 66, 393-398.

25. Hileman CO, Turner R, Funderburg NT, et al. (2016) Changes in oxidized lipids drive the improvement in monocyte activation and vascular disease after statin therapy in HIV. AIDS 30, 65-73.
26. Choi AI, Lo JC, Mulligan K, et al. (2011) Association of vitamin $\mathrm{D}$ insufficiency with carotid intima-media thickness in HIV-infected persons. Clin Infect Dis 52, 941-944.

27. Eckard AR, Tangpricha V, Seydafkan S, et al. (2013) The relationship between vitamin D status and HIV-related complications in HIV-infected children and young adults. Pediatr Infect Dis J 32, 1224-1229.

28. Price PA, Faus SA \& Williamson MK (1998) Warfarin causes rapid calcification of the elastic lamellae in rat arteries and heart valves. Arterioscler Thromb Vasc Biol 18, 1400-1407.

29. Fraser JD \& Price PA (1990) Induction of matrix Gla protein synthesis during prolonged 1,25-dihydroxyvitamin $\mathrm{D}_{3}$ treatment of osteosarcoma cells. Calcif Tissue Int 46, 270-279.

30. Maestro B, Molero S, Bajo S, et al. (2002) Transcriptional activation of the human insulin receptor gene by 1,25-dihydroxyvitamin D(3). Cell Biochem Funct 20, 227-232.

31. Sergeev IN \& Rhoten WB (1995) 1,25-Dihydroxyvitamin $D_{3}$ evokes oscillations of intracellular calcium in a pancreatic beta-cell line. Endocrinology 136, 2852-2861.

32. Lee NK, Sowa H, Hinoi E, et al. (2007) Endocrine regulation of energy metabolism by the skeleton. Cell 130, 456-469.

33. Reddi K, Henderson B, Meghji S, et al. (1995) Interleukin 6 production by lipopolysaccharide-stimulated human fibroblasts is potently inhibited by naphthoquinone (vitamin $\mathrm{K}$ ) compounds. Cytokine 7, 287-290.

34. Foroozanfard F, Jamilian M, Bahmani F, et al. (2015) Calcium plus vitamin D supplementation influences biomarkers of inflammation and oxidative stress in overweight and vitamin Ddeficient women with polycystic ovary syndrome: a randomized double-blind placebo-controlled clinical trial. Clin Endocrinol (Oxf) 883, 888-894.

35. Zia AA, Komolafe BO, Moten M, et al. (2011) Supplemental vitamin $\mathrm{D}$ and calcium in the management of African Americans with heart failure having hypovitaminosis D. $A m J$ Med Sci 341, 113-118.

36. Hopkins MH, Owen J, Ahearn T, et al. (2011) Effects of supplemental vitamin $\mathrm{D}$ and calcium on biomarkers of inflammation in colorectal adenoma patients: a randomized, controlled clinical trial. Cancer Prev Res (Phila) 4, 1645-1654.

37. Brandi L (2008) 1alpha(OH)D3 One-alpha-hydroxycholecalciferol - an active vitamin D analog. Clinical studies on prophylaxis and treatment of secondary hyperparathyroidism in uremic patients on chronic dialysis. Dan Med Bull 55, 186-210

38. Jain SK \& Micinski D (2013) Vitamin D upregulates glutamate cysteine ligase and glutathione reductase, and GSH formation, and decreases ROS and MCP-1 and IL-8 secretion in high-glucose exposed U937 monocytes. Biochem Biophys Res Commun 437, 7-11. 